\title{
Da PROSA LATINA AO VOLGARE: O NASCIMENTO DE UMA IDENTIDADE LINGUÍSTICA PARA ALÉM DA POESIA
}

\author{
Emanuel França de Brito*
}

RESUMO: Neste artigo, busca-se ressaltar o papel da vulgarização de textos latinos, na Firenze do séc. XIII, na formação do panorama cultural em torno da língua volgare. "Natural" e presente não apenas na oralidade como na poesia, essa língua passa a se afirmar gradualmente em estilo culto na prosa, aparecendo em vários gêneros: seja para a difusão de obras tratadísticas da retórica e oratória clássicas, como para obras filosóficas, morais, científicas, historiográficas, didáticas e ficcionais. A partir de então, o conhecimento teórico e as belas letras se dirigem a um público não apenas versado no idioma erudito da época, caracterizando um novo olhar sobre a comunicação escrita cuja expressão mais explícita e objetiva se encontra no Convívio de Dante. Entre as figuras de relevo em tal operação, destacamos Brunetto Latini e a sua Rettorica que, com uma finalidade assumidamente didática, traz do latim para o volgare parte do De inventione ciceroniano.

PALAVRAS-CHAVE: Vulgarização; Brunetto Latini; Dante Alighieri.

ABSTRACT: The focus of this article is to emphasize the role of the vulgarization of Latin texts in Firenze during the XIII Century, in the formation of the cultural panorama around the volgare language. "Natural" and present not only in orality but also in poetry, this language gradually asserts itself in a cult-style in prose, appearing in several genres: either for the diffusion of classical works concerning rhetoric and oratory, as for philosophical, moral, scientific, historiographic, didactic and fictional. From then on, theoretical knowledge and literature are addressed to an audience not only versed in the erudite language of the time, characterizing a new gaze at written communication, whose most evident and objective expression is found in Dante's Convivio. Among the prominent figures in such operation, we highlight Brunetto Latini and his Rettorica, which, with an assumedly didactic purpose, brings part of the Cicero's De invention from Latin to volgare.

KEYWORDS: Vulgarization; Brunetto Latini; Dante Alighieri.

*Emanuel França de Brito - Universidade Federal Fluminense - emanuelbrito@id.uff.br DOI: http://dx.doi.org/10.11606/issn.2238-8281.v0i37p87-94 
RIASSUNTO: In questo articolo è enfatizzato il ruolo dei volgarizzamenti dei testi latini nella formazione del panorama culturale intorno al volgare nella Firenze del XIII secolo. "Naturale" e presente non solo nell'oralità come nella poesia, la lingua volgare comincia ad affermarsi gradualmente nella prosa di alto stile, comparendo in vari generi: sia per diffondere le opere trattatistiche della retorica e dell'oratoria classiche, sia per le opere filosofiche, morali, scientifiche, storiografiche, didattiche e letterarie. Da allora le conoscenze teoriche e le belle lettere possono rivolgersi anche ad un pubblico non solo esperto nella lingua dotta del tempo e dà un nuovo sguardo alla comunicazione scritta, la cui espressione più esplicita e oggettiva si trova nel Convivio di Dante. Tra le principali figure attuanti in tale operazione, ci si ricorda Brunetto Latini e la sua Rettorica che, con uno scopo nettamente didattico, porta dal latino al volgare parte del ciceroniano De inventione.

PAROLE CHIAVE: Volgarizzamenti; Brunetto Latini; Dante Alighieri. 


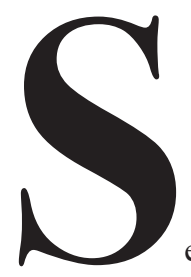

e a Itália politicamente unificada como a conhecemos hoje é fruto de um processo bastante recente (séc. XIX), pode-se dizer que a reunificação da península itálica começa alguns séculos antes, no XIII, ao menos num plano teórico-linguístico que acompanha o declínio da língua latina na fala e a ascensão do volgare florentino na escrita. Serão o Convívio e o De Vulgari Eloquentia, de Dante Alighieri, a propor o projeto de uma língua comum com a qual os intelectuais daquele território poderiam alcançar outros públicos que não somente os mesmos literatos italianos conhecedores do latim clássico. Havia naquele período- na melhor das hipóteses - a consciência entre os escritores das várias partes da península itálica de uma ancestralidade latina que os unia sob uma mesma tradição linguística, aquilo que Dante resume chamando de língua do sì ("sim"), em oposição à língua d'oil da França setentrional e à língua d'oc da Provença (ALIGHIERI, 2015, p. 1209-1213). E é a esses intelectuais itálicos a quem Dante procura delinear todo um potencial daquilo que define como volgare illustre. Ainda sem uma identidade precisa, seria esse idioma uma "língua vulgar" por ser natural e corruptível em comparação ao clássico e incorruptível latim; não seria exatamente vulgar (como entendemos em português) por não manter relação direta com o vulgo (a plebe, o povo), mas uma língua "ilustre" distinguindo-se por qualidades dignas de louvor.

Essa língua, segundo Dante, precisava ser cardinale ("fundamental”), regale ("digna de rei") e curiale (apreciada na cúria, ou seja, nas maiores cortes da Itália); sendo de todas as cidades italianas, e sem pertencer a nenhuma delas; assim, não poderia ser municipale ("municipal"), como a maioria parecia ser, inclusive a aquela falada na sua Florença (ALIGHIERI, 2015, p. 1337).

No que diz respeito à expressão poética em língua vulgar, a declaração mais famosa talvez seja do mesmo Dante (ALIGHIERI, 2015, p. 964), referindo-se aos 150 anos da "breve existência" (picciolo tempo) dos versos escritos em langue d'oc e em lingua del sì. ${ }^{1}$ Com essa declaração, o jovem Dante da Vita Nova reconhece que atrás de si muito já havia sido feito em poesia na língua que ele chamará de "natural”, em oposição à artificial "gramática”. Contudo, no que diz respeito à prosa, o uso do vulgar remonta apenas à primeira metade do '200, com destaque para os Parlamentied epistole de Guido Faba, obra que lançaria as bases para a prosa literária italiana (CEVA, 1965, p. 178). Esse uso do volgare na prosa é feito em paralelo ao uso do latim para, principalmente, adaptar os preceitos da ars dictandi a um novo público essencialmente urbano e envolvido com a administração comunal.

A teoria linguística de Dante no Convívio e no De Vulgari Eloquentia é posterior, portanto,

1 Todo esse material poético encontra-se brilhantemente reunido por Gianfranco Contini nos dois volumes do seu Poeti del Duecento (1960), tendo como base os mais importantes cancioneiros do século XIII: Vat. Lat. 3793, Laurenz. Redi 9, BNCF ex-Palat. 418. 
à realização de outras obras fundamentais para o ambiente cultural em língua itálica como aquele que estava se formando em Florença na segunda metade do séc. XIII. Daquele período são as vulgarizações de obras clássicas e medievais compostas na Toscana, como as de Alberto della Piagentina (De Consolatione Philosophiae, de Boécio), Bono Giamboni (Historiarum adversus paganos, de Paulo Orósio; Epitome de re militari, de Vegécio), Guidotto da Bologna (Rhetorica ad Herennium, pseudo-ciceroniana), Bartolomeo da San Concordio (Catilinario, de Salústio), Andrea da Grosseto/Soffredi del Grazia (De arte loquendi et tacendi, de Albertano da Brescia), BrunettoLatini (De inventione,Pro Ligario, Pro Marcello, Pro rege Deiotaro, todas a partir de textos de Cícero), Domenico Cavalca (Dialogo, de S. Gregório), entre outras, inclusive anônimas, como a das Deche de Tito Lívio, dos Facta et dicta memorabilia de Valério Máximo e do De contemptu mundi de Lotário Diácono. Redigidas a partir da segunda metade do século XIII (posteriores, portanto, a esse primeiro momento, mas não de menor importância nessa formação cultural), são as vulgarizações de Andrea Lancia (Liber de agricoltura, de Paládio; Facta et dicta memorabilia, de Valério Máximo), além daquelas atribuídas a Giovanni Boccaccio e a Francesco Petrarca (Tito Lívio, Valério Máximo).

Para aquilo que se busca aqui destacar, recorremos ao célebre estudo de Gianfranco Folena, Volgarizzare e tradurre, onde ele observa que, muitas vezes, a tradução aparece em posição de destaque no início de novas tradições de língua escrita e literária. Na poesia italiana, o estudioso destaca, por exemplo, a proximidade lexical, semântica e doutrinal dos versos sicilianos de Iacopo da Lentini em Madonna, dir vo voglio aos do trovador provençal Folquet de Marselha em A vos, midonz, voill retrair' encantan tratando-se claramente de uma tradução. (FOLENA, 1994, pp. 8; 23-4).

Na prosa italiana, desse modo, é preciso observar o papel de Brunetto Latini. É a sua tradução do filósofo e orador romano Cícero que Brunetto viria dispor a prosa vulgar de forma ordenada e harmônica a partir do mais alto modelo latino, operação que ninguém havia feito antes dele. E mesmo que um projeto em favor de uma alta prosa italiana só viesse a ser explicitado por Dante poucas décadas depois (no Convívio e no DVE), a operação de Brunetto reúne, “em um exemplo límpido e elegante, as tendências que na metade do Duzentos estavam se afirmando na Toscana, e que teriam fornecido a Dante o material para a criação de uma prosa doutrinal" (SEGRE, 1976, p. 177).

Nascido em Florença por volta de 1220, Brunetto foi essencialmente um homem de cultura, um notário com presente atuação nos círculos administrativos da cidade, tendo sido definido pelo cronista a ele contemporâneo, Giovanni Villani, como o "iniciador e mestre em instruir os florentinos, torná-los desenvoltos no falar bem e em saber guiar e reger a nossa república segundo a Política" (VILLANI, 2007, p. 27-28). Partidário dos Guelfos, grupo que desde o séc. XII defendia a influência papal no governo secular, Brunetto vive os extremos dessa orientação partidária: seja com um degredo que o levou à França justamente no período em que iria redigir as suas maiores obras literárias, seja com posições públicas que lhe conferiram certo protagonismo em oposição aos Gibelinos, que atuavam em favor do domínio do Imperador. 
A sua Retórica, escrita nos primeiros anos da década de 1260, é composta por uma tradução do latim para o vulgar florentino dos dezessete primeiros capítulos do De Inventione, de Marco Túlio Cícero, seguidos de um comentário do tradutor à luz de outros textos latinos. Por esse motivo, a Retórica figura entre as primeiras obras significativas em língua florentina, um idioma que naquele momento ainda era prevalentemente regional, mas que - como sabemos - daria as mais sólidas bases culturais para a afirmação da língua que, séculos depois, passará a ser conhecida como italiana. Imagina-se que tenha sido essa a primeira tradução em língua vulgar de uma obra de Cícero, sendo também o primeiro comentário redigido em vulgara uma obra latina (BARTUSCHAT, 2002, p. 33).

O trecho traduzido e comentado por Brunetto é o que apresenta uma introdução geral sobre a arte retórica, retoma a divisão aristotélica entre os três gêneros da eloquência - demonstrativo, deliberativo e judiciário - e apresenta uma teoria das causas civis, finalizando por mostrar tipos de posturas que podem ser adotadas no início de um discurso (exórdio) ou de um texto epistolar. Notário de profissão, Brunetto fez parte de uma categoria de trabalhadores que tiveram, naquele período, a mediação linguística entre as suas principais funções. Com a Retórica não foi diferente, sendo evidente o esforço do tradutor/autor em oferecer as palavras do filósofo romano a um público não literário, em especial ao seu benfeitor no exílio, durante os anos de aguerridas disputas políticas entre os Guelfos e os Gibelinos.

A Retórica, portanto, foi feita para a curiosidade e deleite do seu "porto", o bom amigo que acolhe o autor em terras francesas, amigo descrito como "um ótimo orador por natureza" e um grande interessado no aspecto teórico da matéria retórica. Brunetto, nesse sentido, apresenta reflexões sobre a presença dessa arte no contexto civil, iniciando o seu comentário pelas palavras de Cícero que questionam as consequências derivadas de uma eloquência que seria nociva se não aliada à sabedoria. É pela imagem de um antigo sábio orador que Cícero apresenta a boa eloquência como civilizadora; no entanto, o destaque não é só para a aptidão da fala, mas também à sabedoria. Apenas com a união dessas duas qualidades é que o exemplo de homem virtuoso teria sido capaz de pacificar uma comunidade de homens selvagens, conduzindo-os a comportamentos dignos de uma vida regida pela razão e pela moral (CÍCERO, 1998, p. 758; LATINI, 1968, p. 13). E ainda que a virtus e a sapientia pertençam a campos distintos do caráter humano, tais qualidades se completam para exprimir a plena capacidade de um líder, que deverá não apenas tomar decisões, mas pô-las em ato dentro da sua comunidade (GRECO, 1998, p. 179).

Em um comentário ao passo ciceroniano que classifica a arte da retórica como inserida naquele gênero definido como parte do conhecimento civil, o mestre retórico Quintiliano (séc. I d. C.) ressalta que dizer "ciência civil" é o mesmo que dizer "sabedoria", aludindo a uma ideia ciceroniana de que a retórica seria a própria civilidade (QUINTILIANO, 2001, p. 238-41; CICERONE, 1998, p. 80-83). E, apesar de muitos outros comentadores terem servido a Brunetto na escrita da glosa que acompanha a tradução, ele parece ter herdado essa concepção independentemente dos intermediários, elegendo a retórica como a mais importante das ciências pela sua 
capacidade de produzir ambientes harmônicos em que prevalece a razão sobre a bestialidade.

Com as vulgarizações de obras latinas, cria-se a ascensão de uma classe erudita proveniente das categorias de juristas, de tabeliães, de literatos, pertencentes menos à aristocracia e mais às linhagens burguesas de grande expressão econômica e governativa; pertencentes, sobretudo, a uma cultura laica já muito atenta à abertura do conhecimento para além dos centros religiosos. Dois são os dados de fato: para a política, os "Ordenamentos de justiça" promulgados por Giano della Bella, em 1293, os quais regulavam o acesso dos nobres ao governo democrático da Comuna e o abria às classes comerciais; e, para a cultura letrada, a autonomia das Universidades, como os centros de Bolonha e de Salerno, que desde o início do século XIII já se distanciavam do ensino no campo estritamente religioso.

Consolida-se, portanto, um novo tipo de intelectual que mantém grande contato com o latim em sua atividade profissional, mas que se mostra, cada um a seu modo, engajado na causa cívica de divulgar as autoridades latinas. Leitores não faltariam, considerando-se os mais de 10 mil jovens alfabetizados somente em Florença, ligados - em sua maioria - às atividades têxteis e mercantis que moviam a economia local, além de uma minoria letrada ligada aos centros religiosos em que prevalecia o latim (VILLANI, 2007, p. 197-202). A isso, some-se o alto número de funcionários públicos, a quem a epistolografia diplomática - ressaltada por Brunetto em seu comentário - seria de grande utilidade.

Pelo que se pode observar, é a gênese do fenômeno tradutológico que acaba por originar uma língua híbrida, um proto-italiano ainda distante dos círculos populares e comerciais, mas que procura se embasar tanto na língua falada dos círculos intelectuais e administrativos da cidade quanto na transposição de termos da língua latina ao volgare florentino. A postura de Brunetto em relação à retórica de Cícero é, assim, inovadora para o período, mas completamente coerente com o que já vinha acontecendo. No exercício da sua atividade profissional como notário, a tradução visava tornar acessível o conteúdo de atos públicos ou particulares àqueles que não tinham o domínio da "gramática", o latim. E no exercício da sua atividade como um homem de cultura, essa mesma necessidade de tradução se daria pela imprescindível tarefa de oferecer aos seus contemporâneos os ensinamentos práticos colocados pela autoridade do filósofo e orador romano Cícero.

O período dos grandes mestres de retórica do séc. XII e XIII que formaram o ambiente no qual Brunetto se insere, havia assistido ao "renascimento do direito romano em conexão como o desenvolvimento do comércio e da vida citadina" (CORE, 2013, p. 97). E Brunetto, mais alinhado a uma interpretação social de Cícero do que seus antecessores, observa a função do orador em estreita conexão com a do condutor de uma comunidade, reconhecendo a importância das autoridades literárias na formação de um homem cívico. Isso é visto, por exemplo, quando ele manipula a origem da palavra rettorica, "mudança mínima, mas estratégica" (ARTIFONI, 1986, p. 702). Substituindo duas vezes no seu comentário o vocábulo rhetor (do grego @̣í retórico, especialista na retórica formal) por rector (do latim regere: quem conduz, rege, controla), Brunetto acaba por sugerir que quem rege é capaz de fazê-lo de modo civilizado unica- 
mente por intermédio da eloquência. Daí provêm o título de "reitor", que atualmente se conserva prevalentemente no âmbito acadêmico, com os diretores de universidades, e no âmbito religioso, com os regentes superiores de ordens. Essa estreita associação de ideias seria um dos motivos pelos quais a disciplina útil ao governo citadino seja lembrada no vulgar do '200 como rettorica, e não como rhetorica ou, simplesmente, retorica, grafias em que a etimologia grega seria mantida. Uma mudança sutil, mas significativa.

O ambiente cultural em que obras como a de Brunetto se inserem - seja como vulgarizações de textos clássicos, seja com textos originais - terá papel fundamental na construção de uma identidade linguística fortemente preservada pelos autores que virão, ainda que vários séculos depois. Se teóricos como Pietro Bembo (1470-1547) preferiram estabelecer a questão dos modelos linguísticos a partir de Petrarca e Boccaccio, cabe observar que o processo de afirmação cultural do volgare - do qual esses dois autores se valem para consagrar suas obras - começou bem antes deles terem nascido; antes mesmo até da composição do De Vulgari Eloquentia, que aborda a discussão naquele primeiro contexto. Assim, se é possível falar em uma prosa que alcança a maturidade na obra de Giovanni Boccaccio, ${ }^{2}$ é apenas devido ao avanço instaurado a partir das vulgarizações e dos manifestos iniciados em prosa quase um século antes do autor do Decameron .

2 A exemplo de Pietro Bembo, que elege os seus modelos para afirmar um caráter "florentino" da língua italiana: Petrarca para a poesia e Boccaccio para a prosa. Cf. BEMBO, Pietro. Prose della volgar lingua [1525]. Introd. e notas de Carlo Dionisotti. Turim: Unione tipografico-editrice torinese, 1966. 


\section{Referências}

ALIGHIERI, D. Vita Nova. In: __.Opere. (Org. Guglielmo Gorni). Vol. I. $2^{\text {a }}$ Ed. Milano: Mondadori, 2015, p. 745-1063. Mondadori, 2015, p. 1065-1547.

De Vulgari Eloquentia. In: __.Opere. (Org. Mirko Tavoni). Vol. I. $2^{\text {a }}$ Ed. Milano: Convivio. In:__opere. (Org. Gianfranco Fioravanti e Claudio Giunta). Vol. II. $1^{\text {a }}$ Ed. Milano: Mondadori, 2015, p. 3-805.

BARTUSCHAT, J. "La Rettoricade Brunetto Latini. Rhétorique, éthique et politique à Florence dans la deuxième moitié du XIIIe siècle". In Arzanà, Cahiers de littérature médiévale italienne. Paris, n. 8, 2002, p. 33-51.

BEMBO, P. Prose della volgar lingua. (Org. Carlo Dionisotti). Torino: Unione Tipografico-editrice Torinese, 1966.

ARTIFONI, Enrico. "I podestà professionali e la fondazione retorica della politica comunale". In: Quaderni storici. Bari, Vol. 2, n. 63, 1986, pp. 687-719.

. "Tra etica e professionalità politica: la riflessione sulle forme di vita in alcuni intellettuali pragmatici del Duecento italiano". In: TROTTMANN, C. (Org.). Vie active et vie contemplative au moyen âge et au seuil de la Renaissance. Roma: École Française de Rome, 2009, p. 403-423.

CEVA, Bianca. Brunetto Latini: l'uomo e l'opera. Milano-Napoli: R. Ricciardi, 1965.

CICERONE, M. T.. De inventione. (Org. Maria Greco). Galatina: Mario Congedo Editore, 1998.

CONTINI, G. Poeti del Duecento. Vol. 2. Milano-Napoli: Ricciardi, 1960.

FOLENA, G.. Volgarizzare e tradurre. $2^{\mathrm{a}}$ ed. Torino: Einaudi, 1994.

LATINI, B. La rettorica. (Org. F. Maggini e Cesare Segre). Firenze: F. Le Monnier, 1968.

QUINTILIANO, M. F. Istituzioni oratorie. (Org. Adriano Pennacini). Vol. 2. Turim: Einaudi, 2001.

SEGRE, C.; MARTI, M. La prosa del Duecento. Milano-Napoli: R. Ricciardi, 1959.

VILLANI, G. Nuova cronica. Org. Giuseppe Porta). Vol. III. Milano: Ugo Guanda, 2007.

Recebido: $12 / 06 / 18$

Aprovado: 14/10/18 